\title{
Cylindrical multipass reflection cells for optical trace gas sensing
}

\author{
Markus Mangold ${ }^{1,2^{*}}$, Herbert Looser ${ }^{3}$, Béla Tuzson ${ }^{1}$, and Lukas Emmenegger ${ }^{1}$ \\ ${ }^{1}$ Empa, Überlandstr. 129, 8600 Dübendorf, Switzerland \\ ${ }^{2}$ IRsweep GmbH, Burgstrasse 20, 8037 Zürich, Switzerland \\ ${ }^{3} \mathrm{FHNW}$, Klosterzelgstrasse 2, 5210 Windisch, Switzerland \\ *markus.mangold@empa.ch
}

\begin{abstract}
Single-piece cylindrical multipass cells effectively fold a long optical path in a small detection volume. We present a systematic survey of various cell configurations and the respective mirror shapes for enhanced path-to-volume ratios.

OCIS codes: (300.6190) Spectrometers; (300.6360) Spectroscopy, laser; (140.3070).
\end{abstract}

The optical path length through a gas sample is a decisive parameter in laser spectroscopy to achieve high instrumental sensitivity and analytical precision. Small absorption signals, either due to a low number density of molecules in gas samples or weak absorption line strengths, are usually compensated for by the use of multipass cells or cavity-enhanced methods. The former approach has led to a variety of cell configurations, the most widely known being those based on the design of White [1] or Herriott [2]. For more compact configurations, variations of a pair of cylindrical or astigmatic mirrors have been proposed $[3,4]$. Nevertheless, the footprint of such multipass cells generally ranges from about $0.2-1 \mathrm{~m}$ with volumes up to $5 \mathrm{~L}$. Since recent advances in thermoelectrically cooled IR laser and detector technologies increasingly allow for compact, easyto-use, and low-cost optical analyzers for multispecies measurements, the optical cell is often becoming the size-limiting element.

We have recently introduced a new design of a gas cell employed for MIR laser spectroscopy [5]. It consists of a single-piece, diamond turned $80 \mathrm{~mm}$ diameter copper cylinder. The cylinder has a single window serving as entrance and exit aperture for the light beam. In the plane of the light beam, a toroidal mirror is carved into the cylinder surface. Due to the concentric arrangement of the toroidal surface, the light beam is refocalized after each reflection. This leads to minimal aberration and reproducible propagation of the laser beam. The top part of Figure 1 shows a simulation of the light path in the toroidal cell. Below the simulation, a photograph shows the experimental realization of the beam pattern. In this configuration, we achieved an optical path of $2.3 \mathrm{~m}$ in a sample volume of less than $40 \mathrm{ml}$ [6]. The excellent path-to-volume ratio leads to a fast response to changes in the gas composition.

Recently, we have evaluated new optical configurations for such single-piece

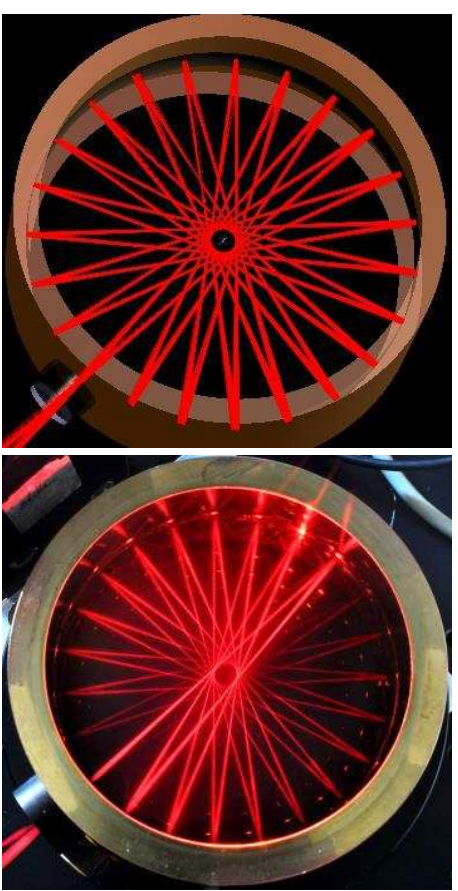

Fig. 1: FRED ${ }^{\circledR}$-simulation (top) and photograph (bottom) of the light pattern in the toroidal gas cell. cylindrical gas cells. The considerations included different mirror shapes such as spherical and parabolic, the comparison of concentric and confocal arrangements as well as the effect of new starpatterns on the stability of the optical alignment. As a result, we have developed a multipass cell, where a parabolic shape in a confocal mirror arrangement is carved into the cylinder wall. The parabolic mirror allows for new optical configurations, e.g. an off-axis beam pattern as shown in the simulation in Fig. 2. Off-axis beam patterns increase the distance between adjacent reflections and thereby minimize the overlap of different optical paths.

Finally, we present a thorough analysis of the shape-accuracy that is required for the successful production of cylindrical multipass cells. We have found that while some parameters are very tolerant with respect to distortions, others have very narrow allowances. This knowledge facilitates the evaluation of new fabrication technologies allowing for low-cost mass-production of cylindrical multipass cells. By this, we aim at making one-piece cylindrical gas cells available for the fast growing mid-infrared gas sensing market. 


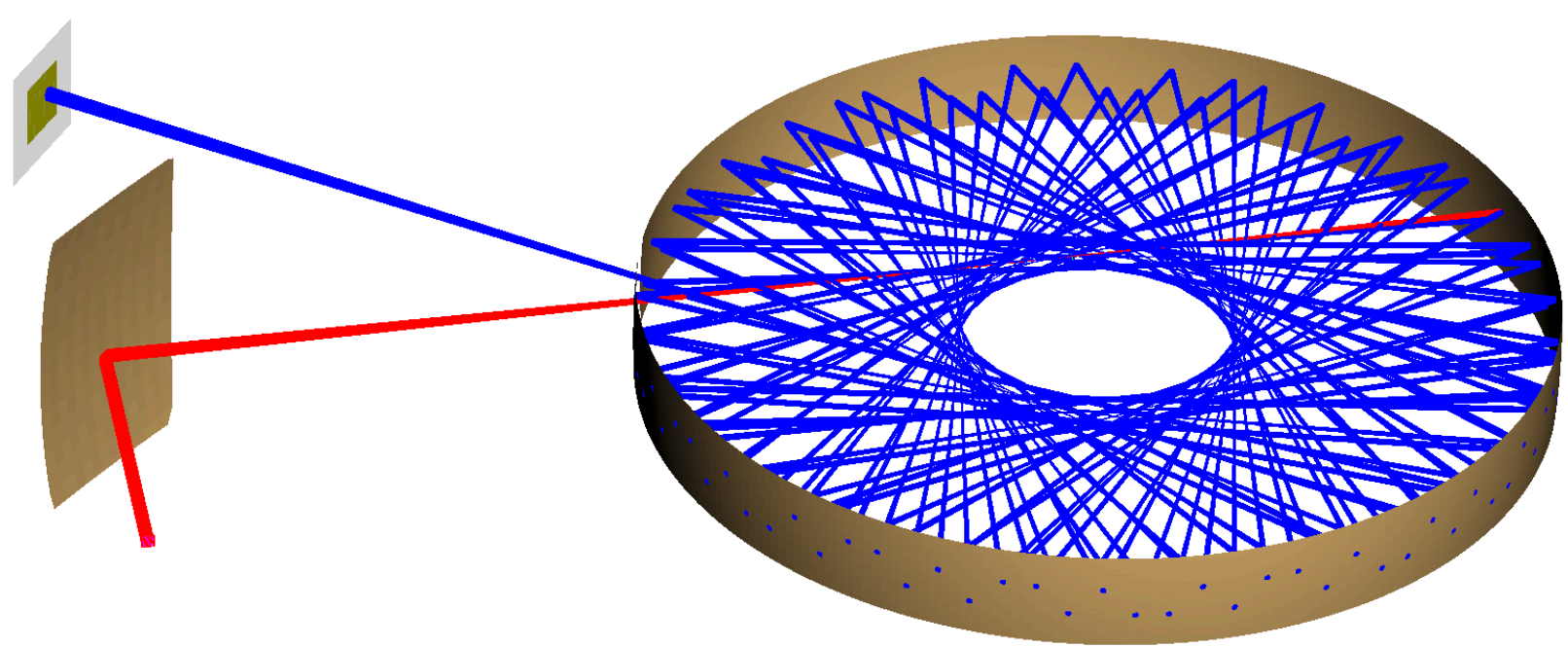

Fig. 2: Simulation of an off-axis beam configuration in a parabolic multipass cell.

[1] J. U. White, J. Opt. Soc. Am. 32, 285 (1942).

[2] D. Herriott, H. Kogelnik, and R. Kompfner, Appl. Opt. 3, 523 (1964).

[3] J. B. McManus, P. L. Kebabian, and M. S. Zahniser, Appl. Opt. 34, 3336 (1995).

[4] J. A. Silver, Appl. Opt. 44, 6545 (2005).

[5] B. Tuzson, M. Mangold, H. Looser, A. Manninen and L. Emmenegger, Opt. Lett. 38, 257 (2013).

[6] P. Jouy, M. Mangold, B. Tuzson, L. Emmenegger et al., The Analyst, DOI: 10.1039/c3an01462b. 